\title{
An evaluation of the usefulness of single pass albumin dialysis: key role of dialysate flow rate
}

\author{
Mariusz Piechota ${ }^{1 *}$ and Anna Piechota ${ }^{2}$ \\ See related research by Sponholz et al., http://ccforum.biomedcentral.com/articles/10.1186/s13054-015-1159-3
}

In their article in Critical Care, Sponholz et al. [1] compared two devices: the molecular adsorbent recirculating system (MARS) and single pass albumin dialysis (SPAD). As Sponholz et al. claim, SPAD is not an effective method for achieving a significant decrease in the concentration of bile acids, creatinine or urea, because a single SPAD procedure induces a $7.62 \%$ (median) reduction in the level of bile acids and an increase in the concentrations of creatinine and urea by respectively $5.04 \%$ (median) and $4.69 \%$ (median), compared with pre-dialysis levels [1]. In contrast, our as yet unpublished study demonstrates that SPAD can effectively reduce not only the level of bile acids but also the concentration of ammonia. Based on our study, the application of the SPAD method with a dialysate flow rate of $1000 \mathrm{ml} / \mathrm{h}$ for a total of around $10 \mathrm{~h}$ reduces the level of bile acids by $21.9 \%$ (median) and ammonia by $16.25 \%$ (median).

A question arises as to the possible causes of such discrepancies. Since continuous venovenous haemodialysis was performed in both studies, the divergence cannot be attributed to the technique. In our view, this divergence is associated with several factors. One of these factors is the difference in dialysate flow rate.
An albumin dialysate flow rate of $700 \mathrm{ml} / \mathrm{h}$ is highly insufficient. Taking into consideration the results obtained by Sponholz et al., an increase in the albumin dialysate flow rate to at least $1000 \mathrm{ml} / \mathrm{h}$ appears to be a necessary precondition to ensure effective elimination of bile acids. Also, the methodology adopted for the study is questionable. In our opinion, comparing the effectiveness of urea and creatinine elimination at radically different dialysate flow rates (SPAD $700 \mathrm{ml} / \mathrm{h}$ vs MARS $2000 \mathrm{ml} / \mathrm{h}$ ) is unjustified and may lead to erroneous conclusions, which in fact occurred [1].

Differences in efficacy between the MARS and SPAD procedures reported in the article in question may also be related to inappropriately selected haemofilters in the extracorporeal blood purification systems under comparison.

Furthermore, Sponholz et al. [1] pointed out metabolic derangements and electrolyte disturbances, particularly in SPAD using regional citrate anticoagulation. In our view, increasing the dialysate flow rate would significantly contribute to preventing the irregularities noted in the study. On the other hand, we believe that the risk of citrate overdose during liver dialysis, but also during continuous venovenous haemodialysis, is very low [2-4].

\footnotetext{
* Correspondence: mariuszpiechota@poczta.onet.pl

${ }^{1}$ Department of Anaesthesiology and Intensive Therapy, Centre for Artificial Extracorporeal Kidney and Liver Support, Dr Wł. Biegański Regional Specialist Hospital, Kniaziewicza 1/5, Łódź 91-347, Poland Full list of author information is available at the end of the article
} 
In our medical centre, we have been successfully performing continuous venovenous haemodialysis procedures with regional citrate anticoagulation in patients with severe liver dysfunction, sometimes for up to several weeks. We have never noted any symptoms of overdose apart from end-stage liver failure.

\section{Authors' response}

Christoph Sponholz ${ }^{1}$, Steffen Mitzner ${ }^{2,3}$, Michael Bauer ${ }^{1,4}$ and Andreas Kortgen ${ }^{1,4}$

${ }^{1}$ Department of Anaesthesiology and Critical Care Medicine, Jena University Hospital, Jena, Germany

${ }^{2}$ Division of Nephrology, Department of Medicine, Rostock University Medical Centre, Rostock, Germany

${ }^{3}$ Fraunhofer Institute for Cell Therapy and Immunology, Extracorporeal Immunomodulation Project Group, Rostock, Germany

${ }^{4}$ Center for Sepsis Control and Care, Integrated Treatment and Research Center, Jena University Hospital, Jena,

Germany

Corresponding author

Andreas Kortgen

Department of Anaesthesiology and Critical Care Medicine, Jena University Hospital, Erlanger Allee 101

07747 Jena, Germany.

Phone: +493641 9 - 323184

eMail: Andreas.kortgen@med.uni-jena.de

We appreciate the interest of Piechota and Piechota in our study. Indeed, SPAD is not a standardised method either with respect to the albumin concentration in the dialysate solution or to dialysate flow rates. The rationale for using dialysis flow rates of $700 \mathrm{ml} / \mathrm{h}$ in our study was based on previously published data on the effective detoxification capacity of a $4 \%$ albumin-containing dialysis solution in vitro [5] and our own experience in critically ill patients [6]. Moreover, the flow rate of $700 \mathrm{ml} / \mathrm{h}$ allows $7 \mathrm{~h}$ of treatment duration similar to MARS using one $5000 \mathrm{ml}$ dialysis bag, resulting in significant changes in total bilirubin levels. However, neither bile acids nor creatinine or urea levels could be reduced in this setting. As discussed extensively, enhancing the dialysis flow rates and treatment times in SPAD could potentially lead to higher detoxification capacities accompanied by higher treatment costs, particularly for higher amounts of albumin. With respect to treatment times the same holds true for MARS, when using a new treatment kit.

Furthermore, Piechota and Piechota raised the question of metabolic and electrolyte disturbances during SPAD administration and citrate anticoagulation in our study. Indeed, we believe that these disturbances were related to the dialysis flow rate, resulting in relative citrate overdosing, and discussed this issue extensively in our publication [1]. Increasing the dialysis flow rate could reduce the risk of citrate overdosing and accumulation. We demonstrated that regional citrate administration can be used effectively and safely in the critical care setting even in patients with severe liver dysfunction $[7,8]$.
We agree with Piechota and Piechota that the dialysis haemofilter impacts on efficacy of SPAD. Reviewing the literature, successful SPAD procedures were published running with different haemofilters, including polysulfone filters as used in the current study (AV1000s polysulfone ultraflux haemofilter; Fresenius Medical Care, Bad Homburg, Germany). Thus, the haemofilter is unlikely responsible for our findings.

To summarise, the SPAD procedure is published to run at different albumin concentrations, dialysis modes and flow rates and with different haemofilters. Currently little is known about the efficacy of SPAD running in different modalities and no review is available summarising all of these issues. Our study thus represents one piece in the puzzle for the discussion of evaluating and standardising the SPAD procedure.

Moreover, our study underlines that the oftenperformed clinical routine of only assessing the course of bilirubin levels to evaluate efficacy of extracorporeal liver support is insufficient.

\section{Abbreviations \\ MARS: molecular adsorbent recirculating system; SPAD: single pass albumin dialysis.}

\section{Authors' contributions}

MP drafted the manuscript. MP and AP contributed to the interpretation of data and critically appraised the manuscript. All authors read and approved the final manuscript.

\section{Competing interests}

The authors declare that they have no competing interests.

\section{Author details}

'Department of Anaesthesiology and Intensive Therapy, Centre for Artificial Extracorporeal Kidney and Liver Support, Dr Wł. Biegański Regional Specialist Hospital, Kniaziewicza 1/5, Łódź 91-347, Poland. ${ }^{2}$ Department of Insurance, Faculty of Economics and Sociology, University of Łódź, Łódź, Poland. 


\section{Published online: 26 May 2016}

\section{References}

1. Sponholz C, Matthes K, Rupp D, Backaus W, Klammt S, Karailieva D, et al. Molecular adsorbent recirculating system and single-pass albumin dialysis in liver failure-a prospective, randomised crossover study. Crit Care. 2016;20:2.

2. Slowinski T, Morgera S, Joannidis M, Henneberg T, Stocker R, Helset E, et al. Safety and efficacy of regional citrate anticoagulation in continuous venovenous hemodialysis in the presence of liver failure: the Liver Citrate Anticoagulation Threshold (L-CAT) observational study. Crit Care. 2015;19:349.

3. Faybik P, Hetz H, Mitterer G, Krenn CG, Schiefer J, Funk GC, et al. Crit Care Med. 2011;39:273-9.

4. Piechota M. Hepatic encephalopathy in the course of alcoholic liver disease - treatment options in the intensive care unit. Anaesthesiol Intensive Ther. 2014;46:34-6.

5. Sauer IM, Goetz M, Steffen I, Walter G, Kehr DC, Schwartlander R, et al. In vitro comparison of the molecular adsorbent recirculation system (MARS) and single-pass albumin dialysis (SPAD). Hepatol Baltim Md. 2004;39:1408-14.

6. Kortgen A, Rauchfuss F, Götz M, Settmacher U, Bauer M. Albumin dialysis in liver failure: comparison of molecular adsorbent recirculating system and single pass albumin dialysis - a retrospective analysis. Ther Apher Dial. 2009;13:419-25.

7. Sponholz C, Settmacher U, Bauer M, Kortgen A. Regional citrate anticoagulation for continuous renal replacement therapy in the perioperative care of liver transplant recipients: a single center experience. Ther Apher Dial. 2015;19:8-15

8. Sponholz C, Bayer O, Kabisch B, Wurm K, Ebert K, Bauer M, et al. Anticoagulation strategies in venovenous hemodialysis in critically ill patients: a five-year evaluation in a surgical intensive care unit. Sci World J. 2014;2014:1-7. 